\title{
Evaluasi Implementasi Sistem Penerimaan Peserta Didik Baru (PPDB) di Kota Balikpapan, Indonesia
}

\section{Evaluation of the Implementation of New Student Admission Systems in Balikpapan, Indonesia}

\author{
I Gusti Putu Darya \\ STIE Madani, Balikpapan, Kalimantan Timur, Indonesia \\ putu_darya@yahoo.co.id
}

Naskah diterima tanggal 26/03/2020, direvisi akhir tanggal 15/04/2020, disetujui tanggal 28/04/2020

\begin{abstract}
Abstrak
Kementrian Pendidikan dan Kebudayaan (Kemendikbud) telah mengumumkan sistem yang digunakan untuk program Pendaftaran Peserta Didik Baru (PPDB) 2019. Melalui Permendikbud Nomor 51 Tahun 2018, prinsip yang dikedepankan dalam Penerimaan Peserta Didik Baru (PPDB) adalah nondiskriminatif, objektif, transparan, akuntabel, dan berkeadilan untuk mendorong peningkatan akses layanan pendidikan. Ada empat peraturan sistem zonasi baru dalam PPDB 2019, yaitu: (a). Penghapusan surat keterangan tidak mampu (SKTM). (b). Domisili lama (c). Pengumuman kapasitas. (d). Prioritas salah satu zonasi sekolah asli. Survei ini bertujuan untuk membuat mengevaluasi implementasi sistem penerimaan peserta didik baru online pada jenjang pendidikan yang meliputi Sekolah Dasar (SD) dan Sekolah Menengah Pertama (SMP). Sesuuai dengan petunjuk teknis Sistem PPDB nomor 420/937/SKT/V/2019. Pada kajian ini diambil sampel sebanyak 26 jenjang pendidikan Sekolah Dasar (SD) dan 23 pada jenjang pendidikan Sekolah Menengah Pertama.(SMP). Disarankan ke depan perlu lebih banyak sosialisasi, dalam rangka keterbukaan, manfaatkan media sosial yang mudah diakses masyarakat, software yang digunakan masih terkendala jaringan perlu dipersiapkan lebih baik lagi, dan waktu pelaksanaan bisa lebih lama sehingga tidak terjadi kepanikan masyarakat untuk mencari sekolah.
\end{abstract}

Kata kunci: Sosialisasi, Zonasi, Keluarga Miskin, dan Pelaksanaan PPDB

\begin{abstract}
The Ministry of Education and Culture has announced the system used for the 2019 New Student Registration program, in Indonesia called "Penerimaan Peserta Didik Baru" (PPDB). Through Ministerial Regulation Number 5, 2018, the principles put forward in PPDB are nondiscriminatory, objective, transparent, accountable, and fair to encourage increased access to education services. There are four new zoning system regulations in PPDB 2019, namely: (a). Elimination of not capable certificate. (b). Old domicile (c). Announcement of capacity. (d). Priority one of the original school zoning. This survey aims to evaluate the implementation of the new online student admission system at the educational level which includes elementary schools and junior high schools. In accordance with PPDB System in structions number 420/937/ SKT/V/2019. In this study, a sample of 26 elementary school and 23 junior high school education were taken. It is suggested that in the future more socialization is needed, in the framework of openness, take advantage of social media that is easily accessible to the public, the software used is still constrained by the network needs to be better prepared. The implementation time could be longer so that there is no panic in the community to look for schools.
\end{abstract}

Keywords: Socialization, Zoning, Poor Family, and Implementation of PPDB 


\section{PENDAHULUAN}

Kementrian Pendidikan dan Kebudayaan (Kemendikbud) telah mengumumkan sistem yang digunakan untuk program Pendaftaran Peserta Didik Baru (PPDB) 2019. Di antara aturan tersebut, sebagian sudah diterapkan sejak 2018. Beberapa perubahan yang dipakai Kemendikbud untuk tahun ajaran ini tertuang pada Permendikbud No.51/2018 tentang penerimaan peserta didik baru tahun ajaran 2019/2020. Melalui Permendikbud tersebut, prinsip yang dikedepankan dalam penerimaan peserta didik baru adalah nondiskriminatif, objektif, transparan, akuntabel, dan berkeadilan untuk mendorong peningkatan akses layanan pendidikan (Permendikbud, 2018).

Sistem zonasi menjadi pertimbangan jarak rumah ke sekolah yang didaftar, masih jadi patokan bagi untuk menerima calon peserta didik baru (Põder et al., 2016; Khasanah, 2018). Zonasi menjadi basis data dalam perumusan kebijakan yang berkaitan dengan peta sebaran distribusi guru, ketersediaan sarana prasarana dan fasilitas sekolah, termasuk wajib belajar 12 tahun (Candiasa et al., 2013; Purwanti et al., 2018). Sistem zonasi mempermudah pemerintah pusat dan daerah untuk memetakan dan memberikan peningkatan akses pendidikan, baik terkait fasilitas sekolah, metode pembelajaran, maupun kualitas dan distribusi guru, sehingga dapat mempercepat pemerataan mutu pendidikan di seluruh daerah (Hakim, 2016; Safarah \& Wibowo, 2018; Purwanti et al., 2019). Tahun lalu surat keterangan tidak mampu (SKTM) menjadi syarat wajib bagi calon peserta yang mengikuti PPDB 2018 lewat jalur keluarga calon peserta didik dari keluarga tidak mampu harus menyertakan bukti keikutsertaan dalam program penanganan keluarga tidak mampu dari pemerintah pusat atau daerah, dan bukan dengan SKTM.

Ada empat peraturan baru sistem zonasi pada PPDB 2019 (Permendikbud, 2019):

1. Penghapusan SKTM

Surat Keterangan Tidak Mampu yang disyaratkan pada PPDB 2018 ternyata menimbulkan banyak polemik. Dalam praktiknya banyak ditemukan SKTM yang tidak sesuai dengan kondisi asli di lapangan. Alhasil, SKTM tak lagi digunakan di PPDB tahun 2019 ini. Selanjutnya siswa dari keluarga tidak mampu tetap menggunakan jalur zonasi ditambah dengan bukti mengikuti program pemerintah pusat, seperti kartu indonesia pintar (KIP), atau pemerintah daerah untuk keluarga tidak mampu.

\section{Lama Domisili}

Pada PPDB 2018, domisili calon peserta didik dibuktikan dengan alamat yang tertera di kartu keluarga $(\mathrm{KK})$ yang diterbitkan minimal 6 bulan sebelumnya. Sedangkan dalam Permendikbud baru untuk PPDB 2019 didasarkan pada alamat KK yang diterbitkan minimal satu tahun sebelumnya. Perubahan ini bertujuan agar tak lagi ada calon peserta didik yang kemudian memalsukan keterangan domisili agar diterima di sekolah yang diinginkan. Kemendikbud akan menindak tegas apabila pada penyelenggaraan PPDB 2019 ditemukan berbagai indikasi kecurangan seperti pemalsuan surat domisili, surat mutasi kerja fiktif, dan praktik jual-beli kursi.

3. Pengumuman Daya Tampung

Untuk meningkatkan transparansi dan menghindari praktik jual-beli kursi, pada peraturan Permendikbud (2018) mewajibkan setiap sekolah peserta PPDB 2019 untuk mengumumkan jumlah daya tampung pada kelas 1 SD, kelas 7 SMP dan kelas 10 SMA/ SMK sesuai dengan data rombongan belajar dalam data pokok pendidikan (Dapodik).

4. Prioritas satu Zonasi Sekolah Asal

Aturan PPDB 2019 ini juga mengatur kewajiban sekolah untuk memprioritaskan peserta didik yang memiliki kartu keluarga (KK) atau surat keterangan domisili sesuai dengan satu wilayah (zonasi) yang sama dengan sekolah asal rumah ke sekolah menjadi pertimbangan utama dalam menentukan penerimaan calon peserta didik.

PPDB menjadi proses administrasi yang dilaksanakan setiap tahun untuk seleksi calon siswa berdasarkan nilai akademik agar dapat melanjutkan pendidikan pada jenjang yang lebih tinggi. Untuk itu, berdasarkan 
keputusan kepala dinas pendidikan dan kebudayaan Kota Balikpapan nomor 420/937/ SKT/ V/2019 telah ditetapkan petunjuk teknis penerimaan peserta didik baru tahun pelajaran 2019/2020. Dengan diterbitkannya keputusan tersebut, maka setiap jenjang pendidikan mulai dari SD sampai dengan SMP di wilayah Kota Balikpapan hendaknya mempedomani penerimaan calon siswa barunya.

Calon siswa yang dimaksud adalah siswa baru yang akan mendaftar pada jenjang SD/SMP Sebelum dilakukan menggunakan sistem online, setiap tahun proses PPDB dilakukan secara manual pada masing-masing Sekolah. Di setiap lembaga pendidikan dalam penerimaan peserta didik baru bertujuan untuk mendapatkan calon siswa yang berkualitas untuk mendapatkan calon siswa tersebut maka harus sesuai dengan aturan-aturan yang telah ditetapkan (Cummings, 2008; Medcalf et al., 2013).

Seleksi yang ditetapkan dalam penelitian ini adalah yang dilakukan dengan cara skoring terpadu rangking terbuka dengan merangking skor nilai komulatif pendaftar berdasarkan nilai usia zonasi maupun ketersediaan ruang belajar untuk Sekolah Dasar dan jalur prestasi akademik dan non akademik untuk Sekolah Menengah Pertama. Oleh sebab itu tidak semua yang mendaftarkan diri sebagai calon siswa tersebut akan diterima, hanya yang memenuhi kriteria seleksi dan sesuai kuota yang telah ditetapkan berdasarkan Peraturan Walikota. Dengan metode rankingan tersebut diharapkan penilaianakan lebih tepat karena didasarkan pada nilai dan bobot yang sudah ditentukan sehingga akan mendapatkan hasil yang lebih akurat terhadap siapa yang akan diterima menjadi siswa. Adapun penelitian ini bertujuan untuk membuat kajian tentang sistem penerimaan peserta didik baru (PPDB) secara online maupun sistem zonasi pada jenjang pendidikan yang meliputi sekolah dasar (SD) dan sekolah menengah pertama (SMP).

\section{METODE PENELITIAN}

Penelitian ini menggunakan metode survei yang dilakukan untuk memperoleh jawaban yang mendalam dari permasalahan penelitian (Sugiyono, 2012; Creswell, 2015). Metode ini digunakan untuk mengumpulkan informasi dari sekolah negeri di bawah naungan Kota Balikpapan.

Dalam penelitian ini, data bersumber dari dinas pendidikan Kota Balikpapan yaitu pendidikan dasar yang menjadi kewenangan dinas pendidikan dan kebudayaan Kota Balikpapan, yang meliputi sekolah dasar (SD) negeri dan sekolah menengah pertama (SMP) negeri yang ada di Kota Balikpapan. Jumlah SD di Kota Balikpapan terdapat pada tabel 1.

Tabel 1. Sumber data

\begin{tabular}{cllll}
\hline No & Kec. Balikpapan & Jml SDN & Jml Sampel & Ket \\
\hline 1. & Utara & 26 buah & 5 buah \\
\hline 2. & Timur & 14 buah & 3 buah \\
\hline 3. & Barat & 8 buah & 2 buah \\
\hline 4. & Selatan & 15 buah & 2 buah \\
\hline 5. & Tengah & 24 buah & 7 buah \\
\hline 6. & Kota & 8 buah & 7 buah \\
\hline TOTAL & $\mathbf{9 5}$ buah & $\mathbf{2 6}$ buah \\
\hline
\end{tabular}

Sumber data: Hasil Survei PPDB 2019

Sedangkan untuk sekolah menengah pertama (SMP) negeri yang disurvei sebanyak 23 sekolah yaitu seluruh SMP negeri yang ada di Kota Balikpapan (sampel jenuh). Total jumlah survei 26 buah SD dan 23 SMP Negeri se-Kota Balikpapan.

\section{HASIL DAN PEMBAHASAN}

Untuk memberikan gambaran tentang hasil survei baik jenjang sekolah dasar (SD) sebanyak 26 sekolah maupun jenjang sekolah menengah pertama (SMP) sebanyak 23 sekolah dapat digambarkan sebagai berikut: 


\subsection{Hasil}

1. Jenjang Sekolah Dasar (SD)

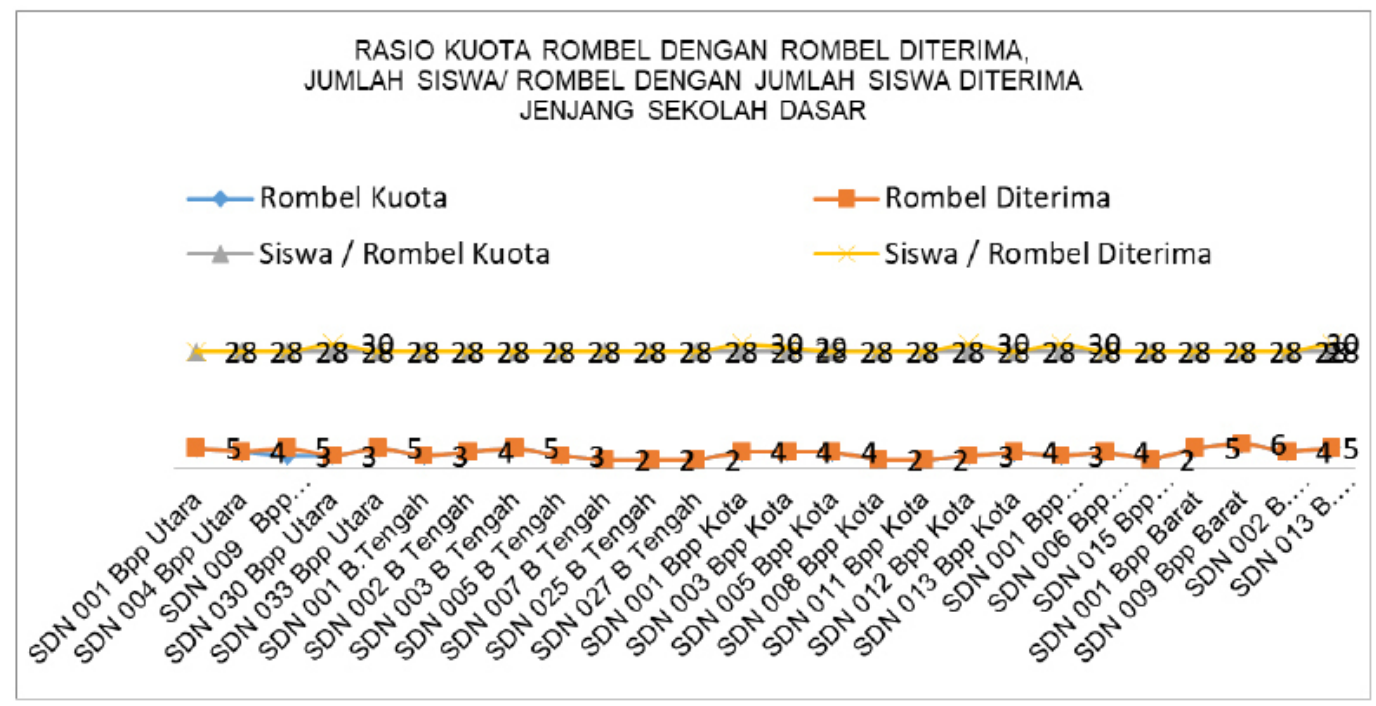

Gambar 1. Jumlah rombel SD

Berdasarkan gambar 1, hasil survei yang dilakukan terdapat satu sekolah yang menerima jumlah rombongan belajar (rombel) melebihi kuota rombel yang ditetapkan sebanyak 3 rombel sedangkan yang diterima sebanyak 5 rombel. Dari 26 sekolah yang di survei, semua sekolah menerima sesuai rombel petunjuk teknis. Terdapat hanya satu sekolah menerima siswa melebihi jumlah rombel kuota.

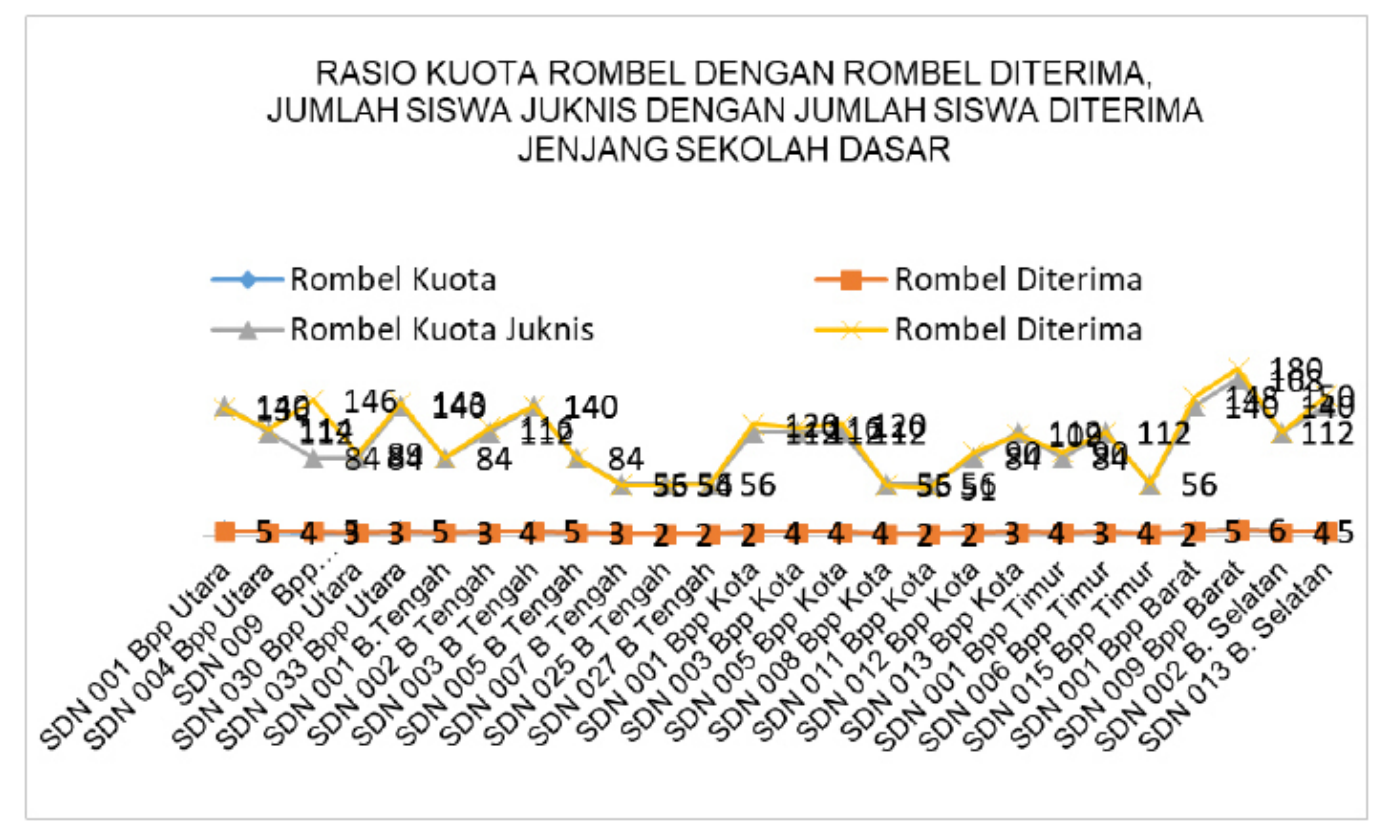

Gambar 2. Kuota per rombel SD

Berdasarkan gambar 2, dari 26 sekolah yang di survei masing-masing kuota per rombel sebanyak 28 orang dan terdapat 6 sekolah yang menerima jumlah siswa melebihi kuota sesuai petunjuk teknis (juknis) yaitu sebanyak 30 siswa per rombel dan satu sekolah menerima 29 siswa per rombel. Dari sisi jumlah siswa yang diterima terdapat 7 sekolah menerima melebihi dari jumlah kuota yang ditetapkan dan sebanyak 7 sekolah menerima dibawah dari kuota yang ditetapkan. Secara total kuota 2.644 jumlah siswa yang diterima sementara secara total yang 
diterima sebanyak 2.726 siswa atau secara keseluruhan terdapat selisih sebanyak 82 siswa, artinya dari 26 sekolah yang di survei terdapat 82 siswa melebihi jumlah kuota. dan jumlah tersebut tidak signifikan jika dibandingkan dengan jumlah sekolah yang ada di Kota Balikpapan.

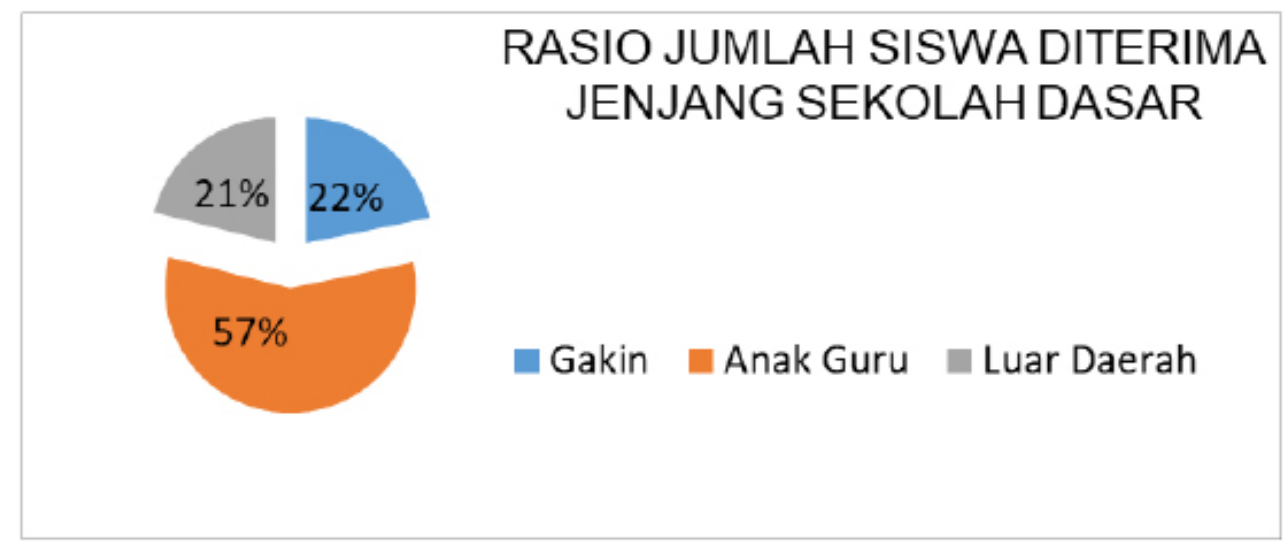

Gambar 3. Rasio jumlah siswa SD

Berdasarkan gambar 3, dari 26 sekolah dasar (SD) yang di survei sebanyak 147 siswa diterima berasal dari sebanyak $22 \%$ siswa termasuk katagori keluarga miskin (gakin), 57\% siswa termasuk anak guru dan sebanyak $22 \%$ siswa berasal dari luar daerah.

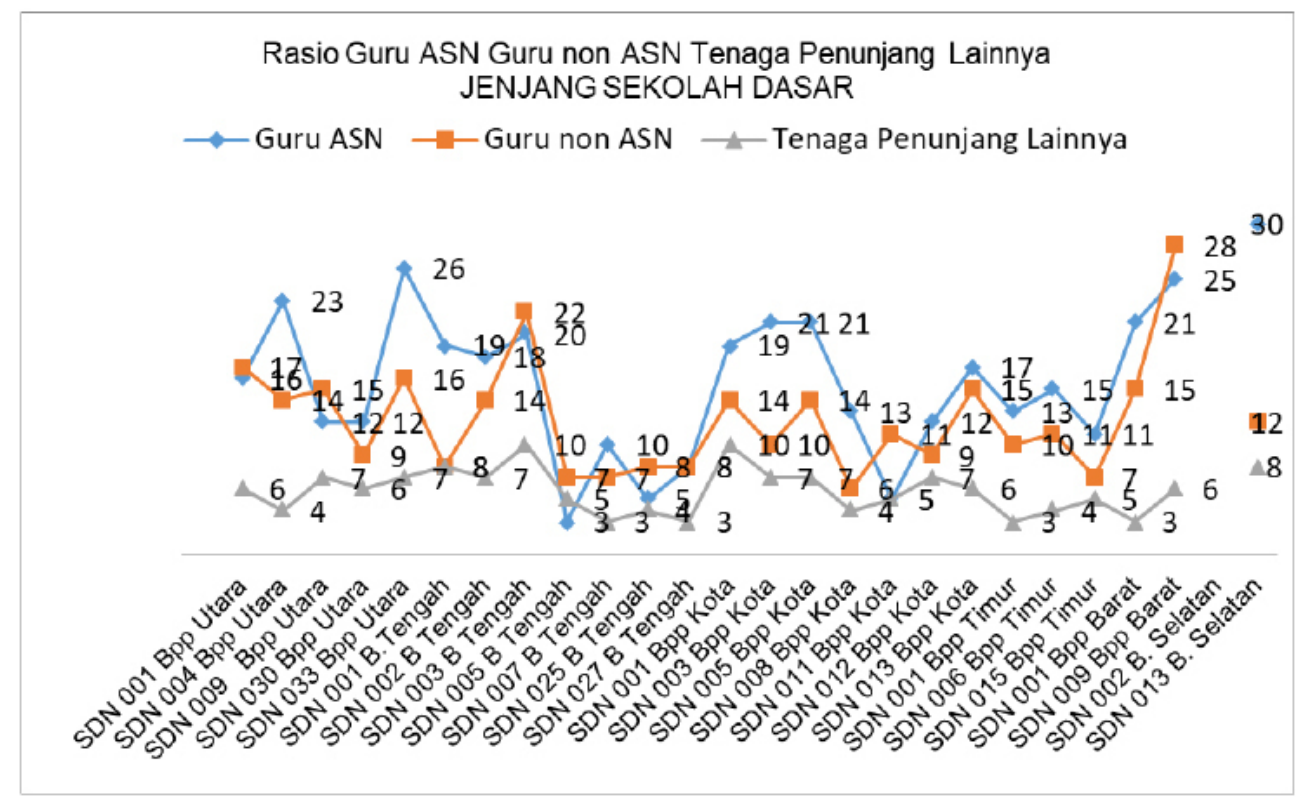

Gambar 4. Rasio guru ASN, non ASN, dan tenaga kependidikan SD

Berdasarkan gambar 4, dari 26 SD negeri di Balikpapan yang di survei, total jumlah sumber daya manusia tenaga pendidik (guru ASN dan non ASN) dan Tenaga Kependidikan (Tenaga Administrasi, Pustakawan, Tenaga Laboran, Pesuruh, Penjaga malam, dan lain-lain) sebanyak 767 orang. Sementara jumlah siswa yang diterima untuk kelas kelas 1 sebanyak 2.726 orang siswa (26 SD yang di survei). Diantara tenaga pendidik (Guru ASN dengan non ASN) rasio 356 orang guru ASN dan 276 orang guru non ASN. Sedangkan tenaga non kependidikan sebanyak 136 orang yang tersebar di 26 sekolah yang di survei.

2. Jenjang Sekolah Menengah Pertama (SMP) 


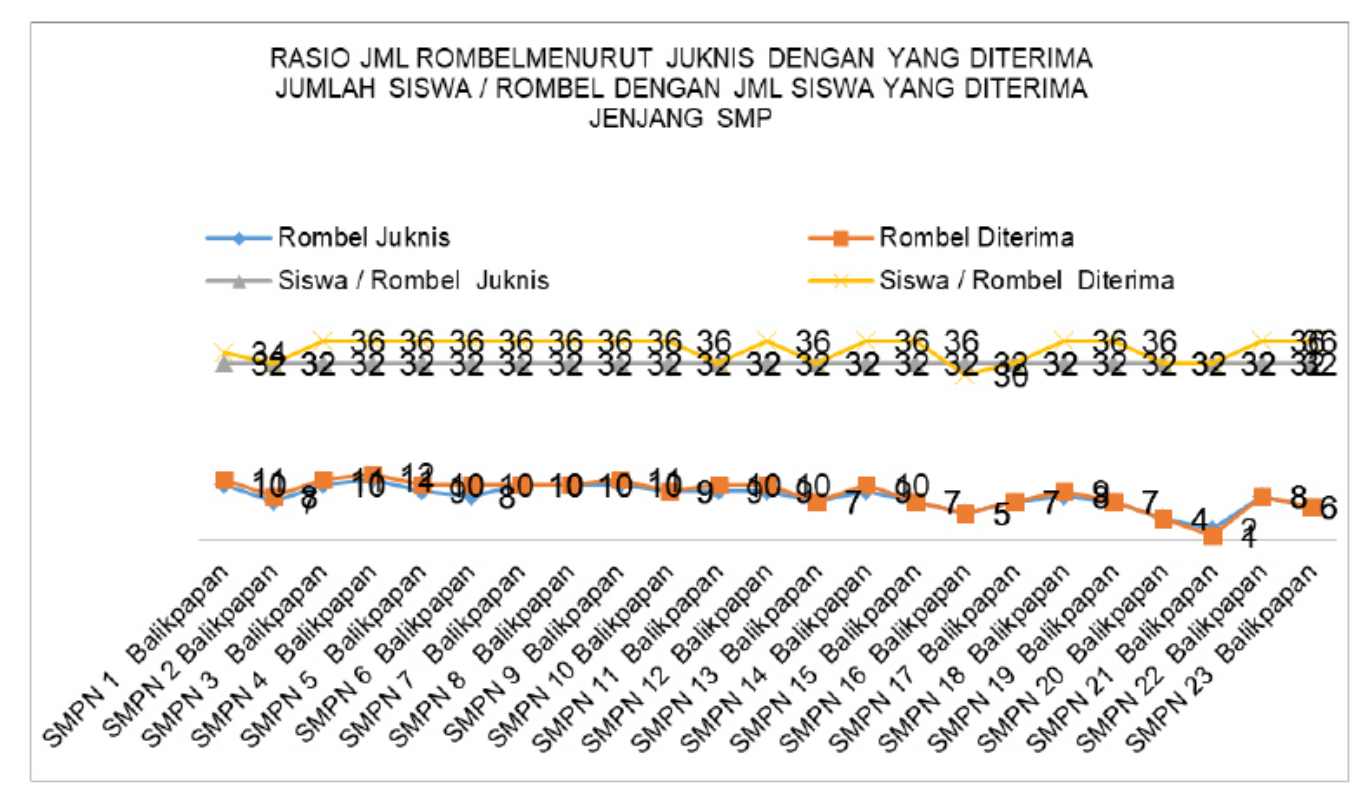

Gambar 5. Rasio jumlah rombel menurut petunjuk teknis SMP

Berdasarkan gambar 5, jumlah rombel seluruh sekolah yang diterima menurut petunjuk teknis (juknis) sebanyak 182 robel sedangkan dalam kenyataan yang diterima sebanyak 193 rombel atau terdapat penyimpangan sebanyak 11 rombel atau bertambah sebanyak 11 rombel. Sedangkan Kuota jumlah siswa per rombel berdasarkan juknis, masing-masing sekolah menerima 32 siswa per rombel, tetapi dalam kenyataan jumlah siswa yang diterima masing masing sebanyak 36 siswa per rombel terdapat pada 15 sekolah dan sebanyak 1 sekolah menambah 2 siswa dari jumlah siswa dalam juknis menjadi 34 siswa per rombel dan sebanyak 1 sekolah menerima 30 orang siswa per rombel, selebihnya sebanyak 6 sekolah menerima jumlah siswa sesuai dengan juknis.

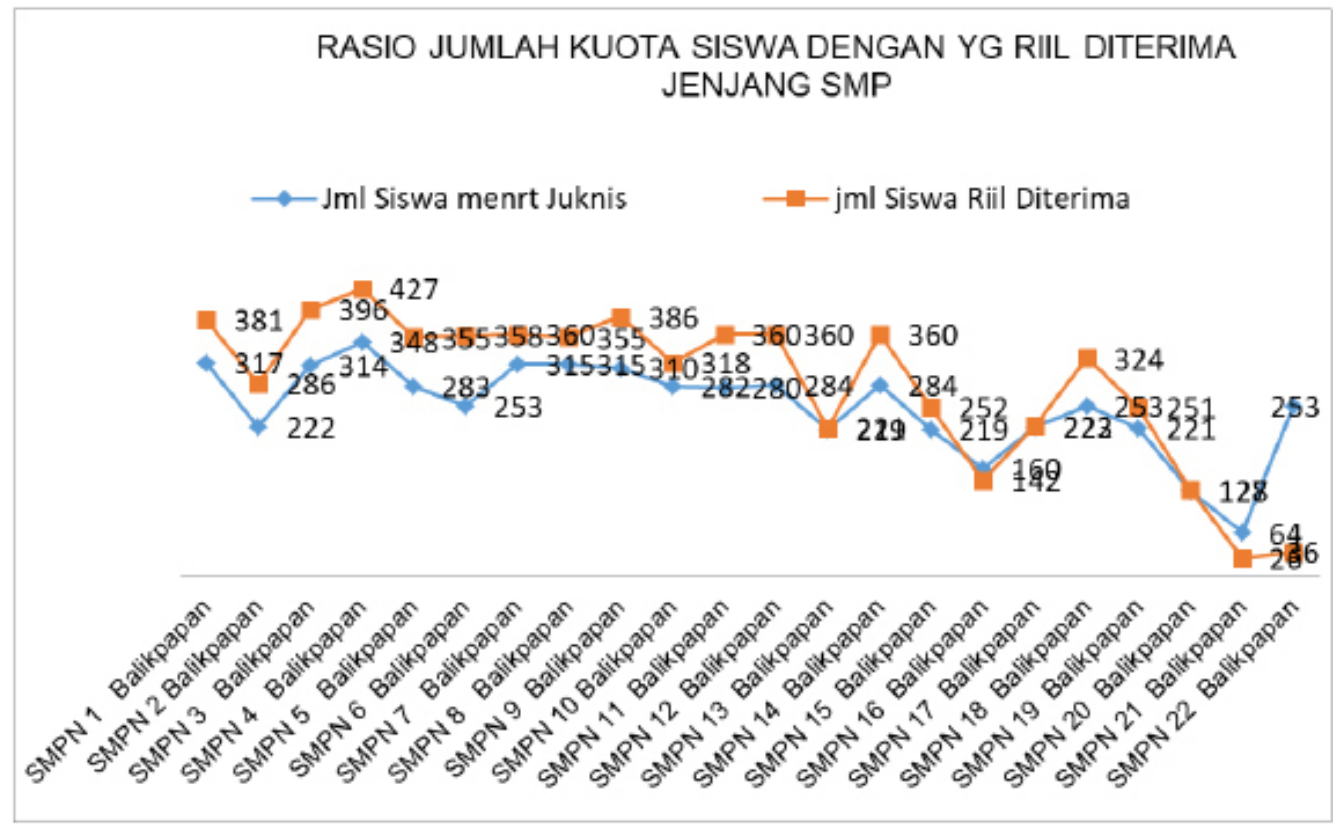

Gambar 6. Rasio jumlah kuota siswa dengan yang rill di terima SMP

Berdasarkan gambar 6, jumlah siswa seluruh SMP negeri di Balikpapan yang diterima menurut kuota sebanyak sebanyak
5.734 siswa, sedangkan dalam kenyataan yang diterima sebanyak 6.521 siswa atau terjadi penyimpangan sebayak 787 siswa 
atau setara 22 kelas. Penambahan jumlah siswa dalam setiap rombel Penyimpangan terjadi karena penambahan jumlah kuota dalam rombel yang semula dari 32 siswa per rombel menjadi 36 siswa per rombel.

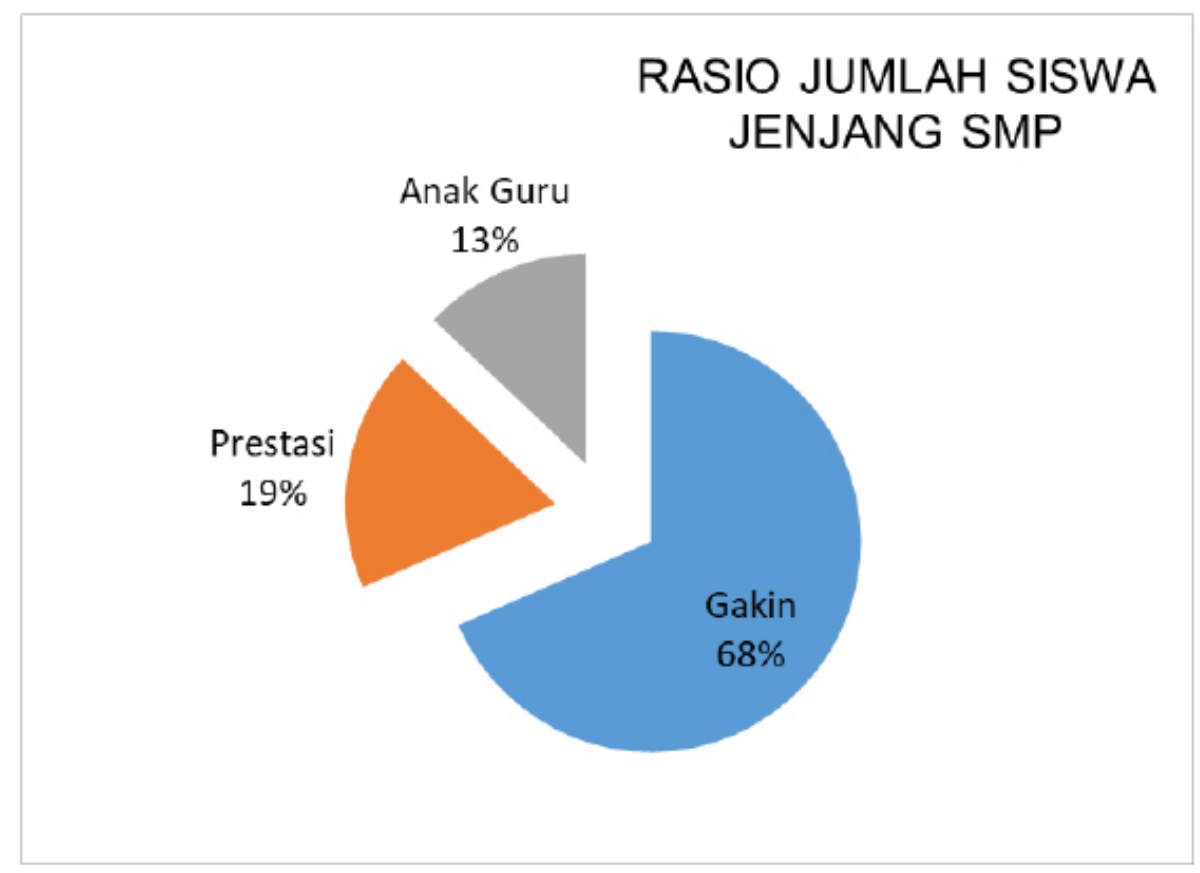

Gambar 7. Rasio jumlah siswa SMP

Dari seluruh SMP negeri Kota Balikpapan yang di survei terdapat sejumlah 987 siswa diterima dengan kreteria $68 \%$ katagori keluarga miskin (gakin), sebanyak
$19 \%$, termasuk katagori prestasi siswa, dan sebanyak $13 \%$ siswa berasal dari anak guru.

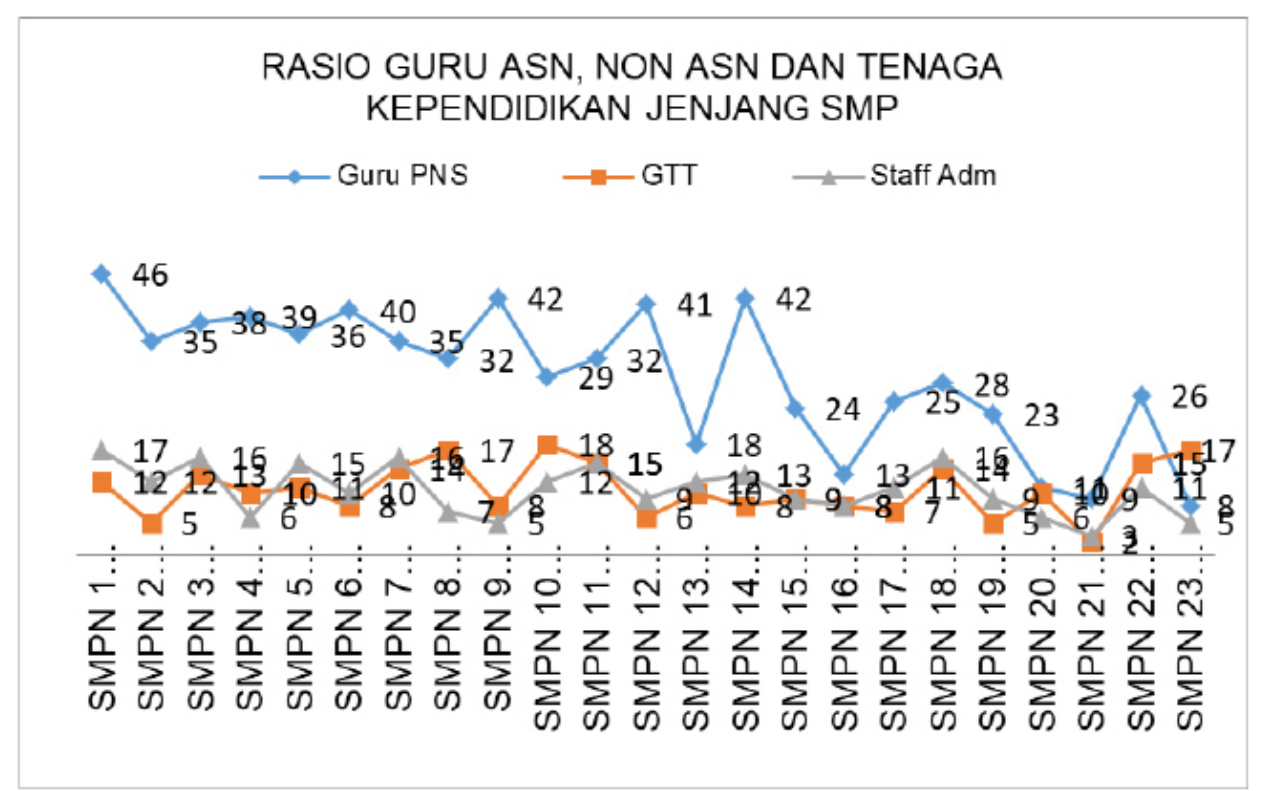

Gambar 8. Rasio guru ASN, non ASN dan tenaga kependidikan SMP

Berdasarkan gambar 8, dari 23 SMP negeri Balikpapan yang di survei, total jumlah sumber daya manusia tenaga pendidikak (guru ASN dan non ASN) dan
Tenaga Kependidikan (Tenaga Administrasi, Pustakawan, Tenaga Laboran, Pesuruh, Penjaga malam dan lain-lain) sebanyak 1.157 orang. Sementara jumlah siswa yang diterima 
untuk kelas 7 (tahun pertama) sebanyak 6.521 orang siswa. Diantara tenaga pendidik (Guru ASN dan non ASN) rasio 672 orang guru ASN dan 242 orang guru non ASN. Sedangkan tenaga non kependidikan sebanyak 243 orang yang tersebar di 243 sekolah negeri. Sementara itu jumlah siswa yang diterima sebanyak 6.521 orang siswa, (tidak dapat diperbandingkan karena tidak menghitung jumlah siswa kelas 8 dan kelas 9).

\subsection{Pembahasan}

Berdasarkan hasil rekap sekolah dasar, dari 26 SD Negeri yang di survei, terdapat 1 sekolah rombel yang diterima melebihi kuota, dimana rombel yang diterima sejumlah 5 sedangkan satandar kuotanya sejumlah 3 rombel. Sekolah tersebut memiliki jumlah penerimaan siswa tertinggi sebanyak 180 siswa sedangkan sekolah dengan penerimaan siswa paling sedikit sebanyak 51 siswa. Salah satu sekolah lainnya menerima siswa dari keluarga miskin (gakin) dengan jumlah tertinggi sebanyak 6 siswa, sedangkan satu sekolah lain menerima siswa luar daerah dengan jumlah tertinggi sebanyak 5 siswa.

Dari sisi fasilitas ruang belajar satu sekolah memiliki jumlah ruangan terbanyak, sebanyak 25 ruangan, sedangkan 2 sekolah memiliki jumlah terendah sebanyak masingmasing 2 ruang belajar. Dari jumlah tenaga pengajar PNS, satu sekolah memiliki jumlah tertinggi sebanyak 30 tenaga pengajar dan satu sekolah memiliki jumlah tenaga pengajar PNS paling sedikit sejumlah 3 tenaga pengajar. Untuk tenaga pengajar non PNS, sekolah yang memiliki jumlah tertinggi sebanyak 28 tenaga pengajar sedangkan sekolah yang memiliki jumlah tenaga pengajar non PNS paling sedikit sejumlah 6 tenaga pengajar.

Berdasarkan hasil rekap sekolah menengah pertama, dari 23 SMP negeri yang di survei, terdapat 10 sekolah yang rombel yang diterima melebihi kuota sedangkan terdapat 1 sekolah rombel yang diterima kurang dari kuota. Sekolah yang memiliki jumlah penerimaan siswa tertinggi sebanyak 427 siswa sedangkan sekolah dengan penerimaan siswa paling sedikit sebanyak 26 siswa. Satu sekolah menerima siswa dari keluarga miskin (gakin) dengan jumlah tertinggi sebanyak 100 siswa, adapun satu sekolah yang menerima siswa berprestasi dengan jumlah tertinggi sebanyak 18 siswa, sekolah yang menerima siswa luar daerah dengan jumlah tertinggi sebanyak 10 siswa.

Analisis strenght, weakness, opportunity, threat (SWOT) pada jenjang sekolah dasar (SD) meliputi:

1. Strenght

Berdasarkan faktor Strenght, hasil survei mendapati bahwa; a) setiap SD telah memiliki petunjuk teknis (juknis) tentang PPDB, sekolah telah membentuk panitia PPDB, setiap SD telah mensosialisasikan Perwali atau Juknis PPDB; b) jumlah ruang belajar di tiap sekolah yang sudah mencukupi; c) jumlah tenaga pendidik PNS maupun honorer serta tenaga kependidikan yang sudah mencukupi di tiap sekolah.

\section{Weakness}

Adapun weakness yang didapat diantaranya; a) masih banyak kendala koneksi pada sistem ; b) perubahan sistem secara tibatiba terkait kuota pembagian wilayah sistem zonasi dalam PPDB masih ada yang tidak merata; c) masih kurangnya koordinasi dan sosialisasi antar instansi (dinas, kelurahan dan sekolah) serta kurangnya jumlah guru untuk siswa berkebutuhan khusus; d) masih adanya ketidaksesuaian data RT/Kelurahan dengan sistem zonasi PPDB seperti kuota beberapa kriteria seperti siswa gakin yang masih terbatas.

\section{Opportunity}

Pada faktor opportunity, faktor-faktor yang memperngaruhi; a) kerjasama dan koordinasi pihak sekolah dengan RT dan Kelurahan untuk dapat lebih mensukseskan sistem zonasi; b) siswa kurang mampu dan berkebutuhan khusus di Balikpapan yang dapat memenuhi kuota PPDB; c) Sistem lintas zona untuk membantu sekolah yang kuotanya tidak bisa tertampung lagi

\section{Threat}

Faktor terakhir yaitu threat meliputi; a) masih terdapat masyarakat yang tidak melengkap dan terlambat dalam mengurus berkas-berkas terkait PPDB; b) pengetahuan dan pemahaman masyarakat tentang zonasi 
yang masih rendah; c) pengetahuan warga masyarakat tentang sistem berbasis on line secara umum masih kurang.

Sedangkan analisis strenght, weakness, opportunity, threat (SWOT) pada jenjang sekolah menengah pertama (SMP) diantaranya:

\section{Strenght}

Berdasarkan hasil survei, faktor strength meliputi; a) setiap SMP telah memiliki petunjuk teknis (juknis) tentang PPDB; b) setiap SMP telah membentuk panitia PPDB; c) setiap SMP telah mensosialisasikan Juknis PPDB; d) jumlah ruang belajar di tiap sekolah yang sudah mencukupi; jumlah tenaga pendidik PNS maupun honorer serta tenaga kependidikan yang sudah mencukupi di tiap sekolah.

\section{Weakness}

Faktor-faktor weakness meliputi; a) sistem PPDB (software) pada hari pertama kurang lancer; b) perubahan kuota pada saat pelaksanaan sistem zonasi PPDB; c) masih adanya keterbatasan kuota untuk penerimaan siswa zonasi; d) belum seimbangnya jumlah lulusan SD dengan daya tampung SMP negeri; e) belum meratanya letak SMP negeri di wilayah Balikpapan sehingga pilihan sekolah terbatas; f) kurangnya guru pendamping untuk siswa yang berkebutuhan khusus; g) kurangnya kuota untuk penerimaan siswa kurang mampu; $h$ ) penerapan skor/poin siswa berprestasi yang tidak berlaku di zonanya; i) biaya internet ditanggung sekolah.

3. Opportunity

$$
\text { Adapun faktor opportunity }
$$

diantaranya; a) penambahan sekolah baru atau penguatan sekolah swasta; b) peran Kelurahan dan Dinas terkait dalam menyediakan data gakin yang valid.

\section{Threat}

Faktor terakhir yaitu threat meliputi; a) pengetahuan dan pemahaman orang tua masih rendah dalam sistem zonasi pada PPDB serta proses pendaftarannya; b) masih adanya masyarakat yang memaksakan diri masuk kesekolah yang tidak sesua; c) zonasi Ketidaksesuaian data jumlah gakin dari tiaptiap Kelurahan; d) banyaknya warga di luar zona yang pindah KK sehingga kuota bertambah; e) sistem PPDB (software) terkendala ketika listrik padam; f) banyaknya siswa kurang mampu yang nilainya di bawah standar; g) kartu Indonesia pintar (KIP) kurang tepat sasaran.

\section{KESIMPULAN}

Pembentukan panitia pendaftaran peserta didik baru (PPDB) pada sekolah masing-masing, serta sosialisasi yang baik menjadi hal yang penting dalam menyukseskan PPDB. Selain itu, kerjasama antara stakeholder terkait sangat dibutuhkan untuk meminimalisir kesalahan pendataan. Kemudian setiap sekolah perlu memperhatikan hal-hal berikut ini agar kegiatan PPDB berjalan dengan lancer diantaranya penggunaan sistem, pemahaman tentang zonasi, pembobotan, dan pemahaman menangani masalah penerimaan siswa yang kurang mampu serta memiliki kebutuhan khusus.

\section{DAFTAR RUJUKAN}

Candiasa, I. M., Ertasari, N. M. S., Semeten, K., \& Sunu, G. K. A. (2013). Pemerataan Dan Peningkatan Mutu Pendidikan Melalui Komunitas Guru Online. Jurnal Sains dan Teknologi, 2(1), 118-127

Creswell, J. W. (2015). Penelitian Kualitatif \& Desain Riset Memilih Diantara Lima Pendekatan. Terjemahan oleh Ahmad Lintang Lazuardi. Yogyakarta: Pustaka Pelajar.

Cummings, W. K. (2008). Policy Options for Access and Equity in Basic Education. In William K. Cummings \& James H. Williams (Eds) Policy-Making for Education Reform in Developing Countries: Policy, Options, and Strategy. USA: Rowman \& Littlefield Education.

Hakim, L. (2016). Pemerataan Akses Pendidikan Bagi Rakyat Sesuai Dengan Amanat Undang-Undang Nomor 20 Tahun 2003 Tentang Sistem Pendidikan Nasional. EduTech J. Ilmu Pendidik. dan Ilmu Sos, 2(1), 53-64

Khasanah, U. L. (2018). Analsis Implementasi Kebijakan Sistem Zonasi Perspektif Stake Holder Sekolah. UIN Malang

Medcalf, N. A., Hoffman, T. J., \& Boatwright, C. (2013). Children's Dreams Viewed Through The Prism of Maslow's Hierarchy of Needs. Early Child Dev. Care, 183(9), 1324-1338

Permendikbud. (2018). Peraturan Menteri Pendidikan dan Kebudayaan Nomor 51 Tahun 2018 tentang Penerimaan Peserta Didik Baru pada Taman Kanak-kanak, Sekolah Dasar, Sekolah Menengah Pertama, Sekolah Menengah Atas dan Sekolah Menengah Kejuruan. Jakarta: Kemdikbud. 
Permendikbud. (2019). Peraturan Menteri Pendidikan dan Kebudayaan Republik Indonesia Nomor 20 Tahun 2019 tentang Penerimaan Peserta Didik Baru pada Taman Kanak-kanak, Sekolah Dasar, Sekolah Menengah Pertama, Sekolah Menengah Atas, dan Sekolah Menengah Kejuruan. Jakarta: Kemdikbud.

Põder, K., Lauri, T., \& Veski, A. (2016). Does School Admission by Zoning Affect Educational Inequality? A Study of Family Background Effect in Estonia, Finland, and Sweden. Taylor Fr. Gr., vol. 3831

Purwanti, D., Irawati, I., \& Adiwisastra, J. (2018). Efektivitas Kebijakan Penerimaan Peserta Didik Baru Sistem Zonasi Bagi Siswa Rawan Melanjutkan Pendidikan. Dinamika 5(4), 1-7

Purwanti, D., Irawati, I., Adiwisastra, J., \& Bekti, H. (2019). Implementasi Kebijakan Penerimaan Peserta Didik Baru Berdasarkan Sistem Zonasi Di Kota Bandung. Jurnal Governansi, 5(1), 12-23

Safarah, A. A., \& Wibowo, U. B. (2018). Program Zonasi di Sekolah Dasar sebagai Upaya Pemerataan Kualitas Pendidikan di Indonesia. Lentera Pendidikan, 21(2), 206-213.

Sugiyono. (2012). Metode Penelitian Kuantitatif Kualitatif dan R\&D. Bandung: Alfabeta. 